\title{
Using Wormholes to Solve the Problem of Evil
}

\author{
NIKK EFFINGHAM \\ University of Birmingham \\ nikk.effingham@gmail.com
}

\begin{abstract}
The Multiverse Response to the problem of evil has it that God made our universe because God makes every universe meeting a certain standard. The main problem for that response is that there's no explanation for why God didn't just keeping making duplicates of perfect universes. This paper introduces the 'Multiactualities Response', which says that God actualises every possible world that meets a certain standard of value. It avoids the corresponding problem about duplication because different propositions must always be true at distinct worlds. The Multiactualities Response nevertheless has its own problem, namely that it requires the possibility of multiple actual worlds. This paper argues that if we consider spacetimes with wormholes, we have good cause to think there can be multiple metaphysically privileged present moments; given a suitable analogy between time and modality, it follows that there can be multiple metaphysically privileged (i.e. actual) worlds. This paper includes an in-depth examination of the metaphysics of both the temporal and modal cases.
\end{abstract}

Keywords: Problem of Evil, Time Travel, Multiverse, Wormholes, Tensed Theory of Time

\section{Introduction}

We all know the problem of evil: (i) God, were He to exist, wouldn't allow any evils to unnecessarily befall people; but (ii) many unnecessary evils befall people; thus, (iii) there is no God. The Multiverse Response (\$2) denies (ii). According to the response, God is obliged to create multiple universes, including both perfect ones and our, imperfect, universe, thus the evils which we suffer are necessary. But there's a big problem for the Multiverse Response, namely the Duplication Objection: Why doesn't God just make an infinite number of perfect universes $(\S 3)$ ?

I argue that a variant theory, whereby there are multiple actual worlds (rather than multiple universes) solves this problem $(\$ 4)$. But that theory relies upon the bizarre idea that there can be 'multiple actualities'. I argue that a 'Dowian' theory of time travel involving wormholes gives us reason to believe multiple present 
moments are metaphysically possible. Since there's a strong analogy between actuality and presentness, I conclude that there can be multiple actual worlds (\$68). Thus, a theory of 'multiple actualities' can resolve the problem of evil.

\section{The Multiverse Response}

This section explains the Multiverse Response to the problem of evil (Forrest 1981; Kraay 2010a; McHarry 1978; Megill 2011; Parfit 1992; Turner 2003). ${ }^{1}$

Take a 'universe' to be a maximally connected spacetime. ${ }^{2}$ Imagine the best possible universe. I'll assume that such a universe is perfect, containing no evil or imperfection. Call it ' $U_{P}$ '. According to the Multiverse Response, God made UP. God also has the ability to make more than just the one universe. Consider a slightly imperfect universe, $\mathbb{U}_{P^{-}}$. U UP ${ }^{-}$is exactly like $\mathbb{U}_{P}$ except for a single pockmark of imperfection e.g. someone briefly having a cold. Were $\mathbb{U}_{\mathrm{P}^{-}}$to exist in addition to $\mathbb{U}_{\mathrm{P}}$ then scads more people would have excellent lives, marred only by a single person's brief and mild illness. Since God can make $\mathbb{U P}_{\mathrm{P}^{-}}$in addition to $\mathbb{U}_{\mathrm{P}}$, God does make it - after all, it' $\mathrm{d}$ be churlish to think that one pockmark of minor evil outweighs the lives of all of the people who'd exist in $\mathbb{U}_{\mathrm{P}^{-}}$.

More universes are possible. Each contains more evil again than $\mathbb{U}_{\mathrm{P}}$. And the same reasoning applies: where the evils aren't so bad that they disqualify the universe from being created, God makes those universes as well. So God makes a whole gamut of universes! The Multiverse Response has it that this includes our own universe. Thus we have an explanation for why our universe contains the evils that it does. Moreover, given the reasoning of the Multiverse Response, we should expect God to make a universe likes ours e.g. one containing the evils we see. Not only are the evils we observe explicable, but they are an expected result of any omnibenevolent deity's creative scheme.

\footnotetext{
${ }^{1}$ One referee pointed out that Kraay is explicitly concerned with the problem of no best world. But Kraay - rightly, in my eyes - considers that problem to be a specific variation of the problem of evil (Kraay 2010b).

2 Alternative views are available. Perhaps spacetime is infinitely big but mainly devoid of matter; 'universes' would then be the intermittent, denser, populated regions (Tegmark 2003). Perhaps spacetime branches and 'universes' are complete branches of spacetime (Saunders and Wallace 2008, 299). Perhaps, when a universe ends, it collapses before expanding back into a new 'universe' (Steinhardt and Turok 2002). Perhaps our $n$-dimensional universe is merely one slice of an $m>n$-dimensional spacetime (Hudson 2008). With little exception (Monton 2010, 6-8), it makes little difference if you opt for an alternative.
} 
The Multiverse Response doesn't say God makes every possible universe. ${ }^{3}$ For instance, a hellish universe wherein every agent suffers terribly, being unjustly tortured for eternity, is a possible universe, but presumably one that God would not make. Some axiological standard must be met by a universe in order for God to create it. Some have suggested:

BEST ON BALANCE: God creates a universe iff that universe contains more good than evil. (McHarry 1978, 133; Turner 2003, 157)

But Best On BALANCE has problems. Problem one: It allows an all-loving God to create people living lives of unremitting suffering just as long as this is countervailed by some other person being better off. Problem two: It's arbitrary. There's nothing ethically or metaphysically special about universe-sized spacetime regions versus any other region, so it's odd for an axiological criterion like BEST ON BALANCE to make them its focus ( $c f$ Climenhaga 2018, 373). For instance, BEST ON BALANCE demands that God doesn't make a spacetime consisting only of a horrendous evil, but it permits God to embed that evil in a spacetime just as long as, trillions of light years away, there is enough sentient life enjoying itself to outweigh that evil. It seems bizarre to me that 'embedding' the evil in a larger region of spacetime makes any difference to the permissibility of allowing it to occur.

This in mind, many alternative axiological principles have been mooted (Kraay 2013, 238-39; Monton 2010, 4-5; Ruhmkorff 2019, 302; Turner 2015, 123). The best such alternative is:

PATIENT-CENTERED CRITERION: God makes a universe iff for every agent in that universe, the life of that agent is worth living (i.e. the agent's own life has more good in it than evil). ${ }^{4}$

PATIENT-CENTERED CRITERION does better than BEST ON BALANCE. It clearly solves the first problem for now, by definition, no agent suffers horribly without some countervailing good to their own life. And it doesn't run into the second problem because it's natural to make agents the focus of value judgements.

Those who accept the Multiverse Response must claim that God will create our universe given the selected axiological criterion. In the case of PATIENT-

\footnotetext{
${ }^{3}$ Thus this theory is distinct from genuine modal realism's claim that there exist infinitely many disconnected spacetimes, one for every metaphysical possibility (Lewis 1986; see also Almeida 2008, 2017; Effingham 2016).

${ }^{4}$ With an eye on free will and divine punishment, you might tweak PATIENT-CENTERED CRITERION to instead say that every agent need only have had the chance to achieve a life worth living.
} 
CENTERED CRITERION, one might worry that at least one agent has a life not worth living. But even though there may be many actual examples of people living horrific lives and then dying, it's dialectically appropriate to assume that every agent receives an infinitely rewarding eternal afterlife. No matter what evils have befallen some actually existing person, after a billion years of post-mortem bliss, it's hard to believe they'd be better off not having existed. So, presumably, our universe would meet the demands of PATIENT-CENTERED CRITERION.

(I admit both that I'm being slightly glib and that more could be said on this matter. But, for the purpose of this paper, I want to set aside these axiological worries and focus instead on the Duplication Objection (q.v.). So assume that our universe (and, later, our world) meets the required axiological standard.)

\section{The Duplication Objection}

The Multiverse Response's big problem is the 'Duplication Objection': ${ }^{5}$ Why, when God makes $\mathbb{U}_{\mathrm{P}^{-}}$, does God make it imperfect? Why not simply duplicate $\mathbb{U}_{\mathrm{P}}$ ? Similarly for every other universe: Won't God always find it preferential to produce more perfection than create imperfect variety? (Monton 2010, 12-19).

Consider the problem in more detail. Imagine UP contains a quadrillion agents, $\tau_{1}, \tau_{2} \ldots \tau_{1 \times 10}{ }^{15}$. Every agent has a perfect life. A bad way of thinking about $\mathbb{U}_{\mathrm{P}^{-}}$is that it's identical to $\mathbb{U}_{P}$ except that one of the agents, e.g. $\tau_{8}$, leads a slightly imperfect life. This is a bad way of thinking because, were God to create $\mathbb{U}_{P^{-}}$in addition to $\mathbb{U}_{\mathrm{P}}$, the agents in $\mathbb{U}_{\mathrm{P}^{-}}$would be distinct from those in $\mathbb{U}_{\mathrm{P}}$; except for $\tau_{8}$, the agents at $\mathbb{U}_{\mathrm{P}^{-}}$would be qualitatively identical to the agents at $\mathbb{U}_{\mathrm{P}}$, but that doesn't make them numerically identical (Kraay 2010a, 360). UP-instead contains

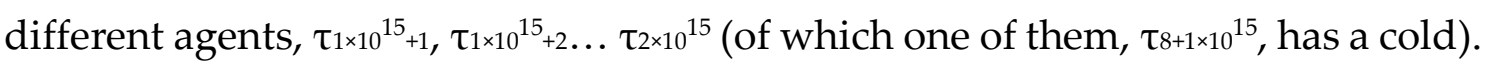
Now the problem is clearer: What purpose could be served by giving $\tau_{8+1 \times 10^{15}} \mathrm{a}$ cold? What would motivate God to do that when it was avoidable?

The literature has three counter-objections to the Duplication Objection. None work.

\subsection{The Impossibility Counter-objection}

The Impossibility Counter-objection says that the Duplication Objection doesn't work because it's metaphysically impossible for God to make duplicates of $U_{P}$ (Kraay 2010a, 360n22; McHarry 1978, 133, Megill 2011, 135; Turner 2003; 150).

\footnotetext{
${ }^{5}$ It isn't the only problem (see, e.g., Johnson (2014) and Rubio (Forthcoming)). But for the purposes of this paper, it is the problem I focus on.
} 
Thus, if God wants to make another universe, it'll have to be an imperfect universe like $U_{P^{-}}$. The reason to think that it's impossible to make duplicates is because the Identity of Indiscernibles is true i.e. qualitative duplicates are numerically identical. (Indeed, if the Identity of Indiscernibles is true, then every agent in $\mathbb{U}_{\mathrm{P}^{-}}$and $\mathbb{U}_{\mathrm{P}}$ will have to differ, at least in some way.)

But I, like most other philosophers, think the Identity of Indiscernibles is false (Black 1952). Other discussants of the Multiverse Response have raised the same concern (Draper 2004, 320; Monton 2010, 13-15). If the Multiverse Response did rely on the Identity of Indiscernibles then the Multiverse Response would be relegated to being a curiosity that only professional philosophers would spend time considering. It'd hardly make for an impressive response to the problem of evil.

\subsection{The Variation Counter-objection}

The Variation Counter-objection says that there's value in there being a variety of differing things. A reality consisting of nothing but duplicates of perfection is not as valuable as a reality consisting of a myriad of much more varied things, even when that variety comes hand-in-hand with imperfection (Parfit 1992; Turner 2003, 147).

There's at least some merit in this response. Imagine I adore M\&Ms. I would nevertheless tire of eating nothing but M\&Ms. Solely in terms of gastronomic value, there is a reason to eat other things even when I consider them less tasty than M\&Ms. Chowing down on a good lentil burger, I can simultaneously acknowledge that M\&Ms are superior but that my (less-than-perfect) burger plays a value-adding role (e.g. helping me appreciate the M\&Ms when I have

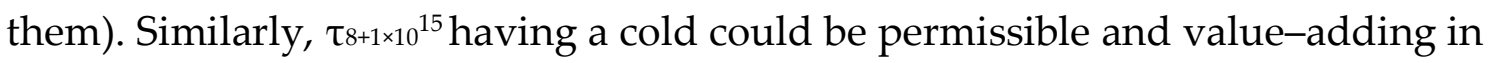
virtue of the variety it adds to what would otherwise be a duplicate of Up.

Ultimately, though, this response strains credulity. Firstly, when we get to the many massacres and horrors that we find in our own history, it's absurd to think that they have been included merely to 'liven reality up a little'. A lentil burger adds variety to my diet and its variation is value-adding, but if you force me to eat a platter of brambles or drink a glass of caustic battery acid, I wouldn't feel the same. We can get value-adding variety without going to such extremes. Similarly, it seems absurd that famines and plagues are added for the sake of variety.

Secondly, the thing which is imperfect may not be the thing which gains value. The event of me eating the lentil burger is imperfect, but it's my life overall which gains the value. Similarly, the Variation Counter-objection requires people to suffer horrific lives in order to make reality as a whole more valuable. But, for the 
same reason that we prefer PATIENT-CENTERED CRITERION to BEST ON BALANCE, this seems repugnant. That God would permit harm to befall agents solely to improve the value of some non-sentient thing (namely, the collection of all universes which compose all of reality) seems obviously immoral. Compare: The Nazi bombing of Guernica resulted in much misery and suffering and it'd be obviously immoral to allow it to happen solely because it results in the production of an inanimate object-Picasso's 'Guernica' — which is of significant value.

In response, one may argue that the variety of pains across the agent's life does add to the agent's own life (as well as adding to the value of reality as a whole). But were the value of the variety you get from the evil in your life enough to outweigh the evils themselves, then we need never mention multiple universes to explain away the problem of evil in the first place. So this attempt to salvage the Variety Counter-objection would undermine the Multiverse Response.

\subsection{The Vastness Counter-objection}

If you have so many things that it's impossible to have any more of those things, say that those things are 'vast in number'. Merely being infinite is not enough to be vast for it's standard to believe that you can add to an infinite number of things e.g. whilst there are an infinite number of odd numbers, you can still add more numbers to them for they are but a subset of all the numbers. So vastness is a 'step above' infinity. (In the literature, we find talk of 'proper class many' things; that's the sort of idea 'vastness' is meant to capture.)

It's debatable whether any things can be vast in number, but let's assume that they can. The Vastness Counter-objection says that God does make duplicates of $\mathbb{U}_{\mathrm{P}}$; indeed, God makes as many duplicates of perfection as He can i.e. makes a vast number of duplicates of Up. By definition, He can then make no more such duplicates. But He can still make more universes by making universes which aren't duplicates of the perfect universe e.g. by making $U_{P^{-}}$. Following through the reasoning of $\S 2$, God ends up making our own universe. (Turner $(2015,114-$ 5) discusses this counter-objection; see also Johnson $(2014,459-61)$ and a related discussion by Monton (2010, 15-16)).

Even if some Fs could be vast, this won't help - at least, not if the way vastness works is at all similar to how other cardinalities function. In the case of other cardinalities, if there are a certain cardinality of Gs which are $F$ then there are (at least) that many Gs. For instance, if you have seven apples then you have at least seven pieces of fruit and if you have beth-7 apples, then you have at least beth7 pieces of fruit. In lieu of a formal theory of vastness, I assume vastness will work much the same. If you have a vast number of apples then you have a vast 
number of pieces of fruit. But if you have a vast number of pieces of fruit, then not only can you make no more apples but you can make no more bananas or pears. Similarly, if God made a vast number of perfect universes then God has made a vast number of universes. And, having made a vast number of universes, God would be unable to go on to make an imperfect universe like Up- or our own. Those supporting the Vastness Counter-objection must therefore provide a theory of vastness that avoids 'vast' acting anything like a normal cardinality in this regard; since that's absent, we should press on.

\section{The Multiactualities Response}

\subsection{Worlds instead of universes}

This paper argues for a new response to the problem of evil, similar to the Multiverse Response, which better avoids the Duplication Objection. I call it the 'Multiactualities Response'. To understand it, we need to clearly distinguish between 'universes' and 'worlds'. By 'universe' I mean some maximally disconnected spacetime (or something along those lines, see $n 1$ ). By 'world' I mean a possible world, as they are standardly understood by modal metaphysicians/logicians. Where universes are concrete spatiotemporal regions, worlds are standardly taken to be some sort of abstract object (e.g. a proposition, or state of affair, or-as I suggest below for the toy theory I introduce for exposition purposes - a fusion of abstract possibilia). ${ }^{6}$ The Multiverse Response says that there are multiple universes. The Multiactualities Response instead says that there are multiple actual worlds (note the focus on actual worlds-it's uncontroversial that there are multiple worlds, but far more controversial that there are multiple actual worlds!). This section describes the Multiactualities Response. The rest of the paper defends it against the charge of unintelligibility on the grounds that it makes no sense to talk about 'multiple actualities', 'multiple actual worlds' etc.

The basic idea of the theory is as follows. God knows what possibilities there are and, being omnipotent, it's within His power to make some possibility actual; we can say that God 'actualises' the corresponding possible world. For instance, if God brings into being an arrangement of matter across spacetime such that I win the lottery, then we would say that God actualises a world at which I win the lottery. The controversial claim of this paper is that God can actualise multiple

\footnotetext{
${ }^{6}$ Famously, Lewis (1986) argues that worlds are disconnected spacetimes. Set aside this 'genuine modal realist' view. Genuine modal realists have their own responses to the problem of evil (Almeida 2008, 2017; Effingham 2016) and so probably won't be interested in the argument of this paper in the first place.
} 
worlds i.e. that there can be multiple actual worlds. If that controversial claim is true, God should actualise every world which meets the appropriate axiological criterion (i.e. of every agent at it having a life worth living). All other worlds remain unactualised. Since we live in a world which (allegedly) meets the axiological criterion, God actualises our world. We again have an explanation for why we see the evils around us.

Return to the Duplication Objection and see why the Multiactualities Response fares better. With universes, God creates two of them, a perfect one and a nearperfect one. The problem is then why God didn't instead just make two indiscernible perfect universes? But similar thinking doesn't apply to multiple actual worlds. It's natural to believe that worlds, actual or otherwise, are individuated by what's true of them, i.e.:

WORLD INDIVIDUATION: World $w_{1}$ and world $w_{2}$ are the same world $\leftrightarrow$ for every proposition $\varphi: \varphi$ is true at $w_{1} \leftrightarrow \varphi$ is true at $w_{2}$.

WORLD INDIVIDUATION entails that there cannot be two indiscernible worlds. If God actualised both a perfect world and a slightly blemished near-perfect world, He can't make the latter perfect without having merely actualised just one world. That is: If God tried to make a near-perfect universe otherwise perfect, He would succeed, but if God tried to make a near-perfect world otherwise perfect, He would instead have actualised a different world.

One may doubt WORLD INDIVIDUATION. But it's eminently plausible. Firstly: It's intuitive. If, in chess, you are told there are three ways to win a match, you'd be confused if those 'three ways' consisted of precisely the same set of moves. Similarly, if possible worlds are 'ways the world can be', it's bizarre for there to be distinct worlds of which everything true of them is the same. Secondly: WORLD INDIVIDUATION drops out of many ersatz theories of possible worlds. It obviously drops out of an identification of worlds with sets of propositions. Other ersatz theories will likewise entail it (e.g. a combinatorial theory) or will do so when supplemented with some reasonable assumptions (e.g., assuming properties are individuated by their causal and nomological roles, it follows from the identification of worlds with universals).

Therefore, whilst God may be able to create duplicate universes, He can't actualise duplicate worlds.

\subsection{Modal Metaphysics}

Having introduced worlds, it's perspicuous to introduce a metaphysical system for discussing such worlds. My chosen system comprises two claims. 
First claim: At every world an object exists at, it has a modal part at that world (Graham 2015; Wallace 2014). 'Modal part' is defined thus:

$x$ is a modal part of $y$ at $w=\mathrm{df}$ (i) $x$ exists at, and only at, $w$; and (ii) for every $z, z$ overlaps a part of $y$ at $w \leftrightarrow z$ overlaps a part of $x$ at $w$.

We then add:

$x$ is $F$ at $w \leftrightarrow x^{\prime}$ s modal part at $w$ is $F .^{7}$

E.g., since it's possible for me to be a fisherman, or a cyborg, or married, I have modal parts which are fisherman, cyborg, and married.

Second claim: Modal parts that don't exist at a world which is actual are abstract, not concrete. That is, rather than being a Lewisean (whereby possible worlds and their contents are concrete physical things), I'll assume a 'Williamsonian' ontology (whereby things which aren't actualised are abstract). So, for instance, my modal part which is a cyborg exists, but it is an abstract object. Similarly, my non-actual sister is composed solely of abstract modal parts (and thus is, herself, an abstract object).

These modal parts have intrinsic properties and stand in relations to one another. Being abstract, though, it's not as if they're married, or a cyborg, or a fisherman (for only concrete things can get married, have bionics, or go fishing). Instead, modal parts have ersatz properties and stand in ersatz relations corresponding to those properties/relations. Use a subscripted $\xi$ to mark out those properties/relations. Some of my modal parts are thus $\operatorname{married}_{\xi}$, a $\operatorname{cyborg}_{\xi}$, a fisherman $\xi$ etc. Indeed, my actual modal part also has these ersatz properties, for instance it's a philosopher $\xi$. Being actual, it's also a philosopher. That in mind, say:

PROPERTIES $\xi$ /Properties: $\forall x\left(\left(x\right.\right.$ is a modal part $\wedge x$ is actual $\left.\left.\wedge F_{\xi} x\right) \supset F x\right)$

Finally, given these two claims, it's then natural to say that worlds are composed of modal parts i.e. a world $w$ is identical to those modal parts which exist at $w$. (Note that, just as other ersatz theories of worlds fail to analyse modality, this system will also fail to analyse modality, since it'll be a brute fact as to what collections of modal parts compose a world.)

\footnotetext{
${ }^{7}$ In the terminology I introduce below, that equates to saying: $x$ is $F$ at $w \leftrightarrow$ the modal part of $x$ which is a part of $w$ is $F \xi$.
} 


\subsection{Problem: The Axiological Status of Multiple Actualities}

That metaphysical system in place, we can more easily understand the problems facing the Multiactualities Response. The big problem is how to make sense of their being multiple actual worlds. But, before we turn to that, consider the following: Why would God bother to actualise multiple worlds? With the Multiverse Response, this was less of a problem. Clearly God should make more universes, we might think, because you end up with more agents—that is, agents numerically distinct from one another-leading valuable lives. But, given the Multiactualities Response, the agents are (transworld) identical and things aren't as clear-cut. In short: If God actualises a world where we all have perfect lives, what reason would God have for actualising another world where we also have less well-off lives?

But God does have a reason. Compare it to a temporal case. Imagine I have an excellent life for fifty years. I am then faced with a choice: (i) die and cease to be; (ii) live on, but with a less-than-excellent life (although a life which is still worth living). Clearly, I should rationally opt for (ii). It's prima facie good for there to be more temporal parts of me, even when those temporal parts are having a lessthan-great time than some other temporal parts of me. More temporal parts is ceteris paribus more valuable.

Similarly, even though God has made modal parts of me which are experiencing perfect lives, that doesn't mean that my having more modal parts isn't better. And that applies even when those modal parts aren't as well off as some perfect modal parts. I should be glad that God brought my actually existing modal parts into being; that there are other modal parts of me having a much better time is by-the-by.

\subsection{Problem: The Intelligibility of Multiple Actualities}

The Multiverse Response requires multiple universes. That it's possible for there to be multiple universes is readily accepted. But that there could be multiple actual worlds should initially strike you as unintelligible. This, more serious, problem is the focus of the remainder of this paper. There are two ways of understanding this problem.

The first way is an incredulous stare. Once one understands what it is for a world to be actual, you might think it's simply impossible to conceive of multiple worlds being actual.

The second way pads out that incredulity with arguments. Argument one: If God makes one world actual, were He to try to make another world actual, then what $\mathrm{He}^{\prime} \mathrm{d}$ end up instead doing is make one enormous actual world consisting of disconnected island universes. Argument two: Imagine $P$ is true at one world 
and false at another. God actualises both worlds, thus (where ' $A$ ' is the 'Actually...' operator), $\mathbf{A} P \wedge \mathbf{A} \neg P$ is true. If we assume either of:

$$
\begin{aligned}
& \text { FACTIVITY OF ACTUALITY: A } \varphi \supset \varphi \\
& \text { COMMUTATIVITY OF } \neg / A: A \neg \varphi \leftrightarrow \neg A \varphi
\end{aligned}
$$

Then we get a contradiction i.e. $P \wedge \neg P$ in the first case and $\mathbf{A} P \wedge \neg \mathbf{A} P$ in the second.

\section{Multiple Nows}

Let's start with the incredulous stare. Assume the standardly held position that there's a strong analogy between time and modality - specifically, between 'the present' and 'the actual world'. The argument of this section is that, since there are already views which allow for there to be multiple nows, the idea of there being multiple actualities isn't absurd.

Dowe (2009) considers worlds where (i) tensed theory is true (i.e. the present moment is in some sense 'metaphysically privileged') and (ii) time loops back on itself (for more on 'looping time' see (Effingham 2020, 17-19). For purpose of example, we'll see how this works with a flatland universe consisting of two spatial dimensions such that the universe is a spatial circle. Extending it in the temporal direction, the shape of the spacetime depends upon whether time is linear or whether it loops. If linear, it' $\mathrm{d}$ form a cylinder. If it loops, it forms a torus. Given tensed theory, at different times, different vertical slices of the cylinder/torus would be metaphysically privileged. In the case of the toroidal 'looping' spacetime, the metaphysically privileged present moment keeps looping around, repeatedly illuminating the same segments of the spacetime. See figure 1. There can also be cases where only a part of the spacetime forms a temporal loop, for instance if there were wormholes which connect the present with the past (Effingham 2020, 19-22). See figure 2.

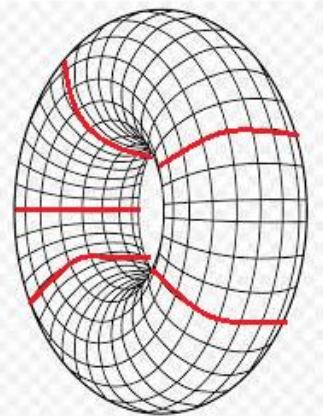

Figure 1

A Toroidal Tensed Spacetime

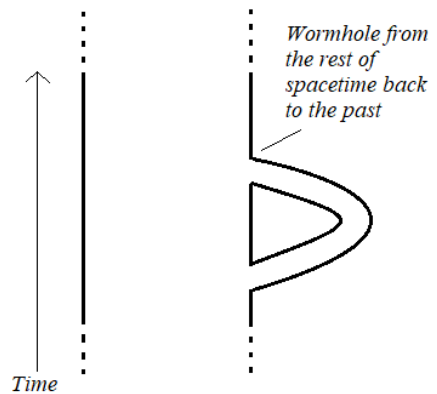

Figure 2

A (non-toroidal, non-'looping')

spacetime including a wormhole which leads into the past 


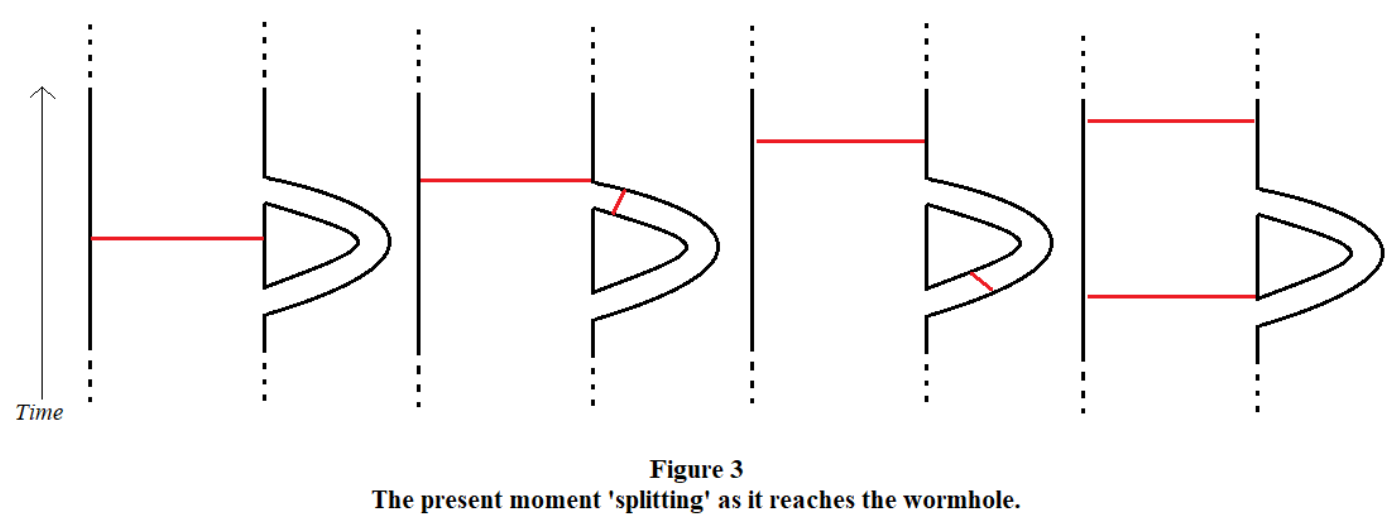

Dowe develops different models of tensed time for understanding these spacetimes. One of the models has it that the segment of spacetime which is metaphysically privileged 'splits off' when it reaches the wormhole (Dowe 2009, 660-61). The portion which has split off ultimately arrives back in the past, at which point a region of spacetime that was once present is now present again, as well as what we'd call 'the present moment' back in the future (see figure 3). Wormholes are 'now-duplicators' (Dowe 2009, 663). ${ }^{8}$

That model bears out exactly what I need i.e. a case of multiple present moments. Were I to knowingly travel through the wormhole to the past, when I arrive I should believe that not only do I enjoy the metaphysical privilege afforded to those people and things which are around me, but so too do those I left behind in the future. This is the kernel of my argument. Granting the coherency of this 'Dowian theory', we should grant the coherency of multiple nows. And if multiple nows are coherent then-since modality and temporality are analogous - we should grant the coherency of multiple actualities. Thus the Multiactualities Response to the Problem of Evil avoids the unintelligibility problem. And note that Dowe's theory is not the only theory in this neighbourhood; there are other theories which accept the possibility of multiple presents. Spoalore and Torrengo (Forthcoming) argue that the moving spotlight theory can make room for 'multiple nows' and Goff (2010) similarly has a time travel theory which makes multiple moments 'present'.

The rest of this paper delves into the details of a metaphysical system bearing out multiple nows and multiple actualities, explaining how to avoid the arguments from $\S 4.4$.

\footnotetext{
${ }^{8}$ Dowe considers the model inferior to a competing model. But he does not consider it absurd $(2009,663)$. That is, he considers it a plausible model.
} 


\section{The Metaphysics of Multiple Nows}

\subsection{Tensed Theories of Time}

To understand more about the metaphysics of the Multiactualities Response, I'll start by developing the metaphysics of the temporal case (\$6) before extending it to the modal case (\$7).

The Dowian theory makes clear why we might want to say multiple moments can be present, but doesn't say much about the specific metaphysical details which would allow multiple moments to be present. Certainly, not every tensed theory can make room for multiple nows. For instance, orthodox growing block theory says:

$t$ is the present moment $=_{\mathrm{df}}(\mathrm{i}) t$ is concrete; and (ii) no other time is both concrete and later than $t$.

That version of growing block theory has a metaphysics straightforwardly inconsistent with there being multiple nows. This section develops a tensed theory which instead allows for multiple nows.

First of all, I'll assume that there's a grounding relation, which I'll take to be a relation between facts (Bliss and Trogdon 2014). For example: facts about tables existing are grounded in facts about atoms being arranged in a certain way; facts about pieces of cheese having holes in them are grounded in facts about the arrangement of parts which compose the cheese; a Platonist might say that facts about some $x$ being $F$ is grounded in facts about $x$ instantiating Fness. Derivative facts are those which are grounded; fundamental facts are those which are not grounded by any other facts.

Grounding theorists tend towards a permissive ontology (Schaffer 2010a, 35662). Gerrymandered mereological sums, numbers, properties, propositions, possibilia, fictional objects etc. all exist in a permissive ontology. What's at stake, metaphysically speaking, is not whether they exist, but what facts explain their existence i.e. what explains the relevant 'existential facts'. If we assume a permissive ontology then past/future objects exist (just like everything else exists). E.g. Rose the T-Rex exists even though she died 66 million years ago. Further, if we assume ontology is permissive, some form of perdurantism is true and things have temporal parts. E.g. $r$, being an instantaneous temporal part of Rose, did exist-thus, given permissivism, also exists simpliciter. This doesn't mean eternalism is true, however. Eternalists would further add that Rose, and $r$, are concrete; even if our ontology is permissive, we needn't add that these things are concrete, instead taking past/future things (like Rose and $r$ ) to be abstract (just like numbers, propositions, etc.). I'll assume exactly this i.e. I 
endorse a Williamsonian ontology whereby things eternally exist, but are intermittently concrete.

Next, consider the properties of the Williamsonian existents and the relations between them. In eternalist ontologies, this is straightforward e.g. $r$ would be five metres tall, weigh eight tonnes, and stand in the '66 million years earlier' relation to my current temporal part. But I've denied eternalism. Instead, $r$ is abstract and currently unlocated in spacetime, so $r$ can't be any metres tall, nor have any weight, nor be earlier or later than anything. Instead $r$ has 'ersatz' properties/relations. Using the subscript ${ }_{\varepsilon}$ to denote such properties/relations, $r$ is five metres tall $l_{\varepsilon}$, weighs eight tonnes $\varepsilon_{\varepsilon}$, and is 66 million years earlier $_{\varepsilon}$ than my current temporal part. In the case of $r$, and all instantaneous temporal parts in general, the ersatz properties correspond to the properties they would have were they present, from which it follows that:

PROPERTIES $\varepsilon$ /PROPERTIES: $\forall x$ ( $(x$ is an instantaneous temporal part $\wedge x$ is present $\left.\left.\wedge F_{\varepsilon} x\right) \supset F x\right)$

All this in place, move to detailing which facts are fundamental. I will assume there are two types of fact: tenseless facts and tensed facts.

The first type, tenseless facts, never change. Hewing to the standard position that mereologically simple things are meant to be more fundamental than composite things, the fundamental tenseless facts will be a set of existential facts about the existence of mereologically simple (i.e. spatially and temporally simple things), the properties $s_{\varepsilon}$ of those things, and the relations $\varepsilon$ between them. ${ }^{9}$ The fundamental tenseless facts then ground all of the existential facts and facts concerning the properties $_{\varepsilon} /$ relations $_{\varepsilon}$ of everything. For instance, fundamental tenseless facts ground the existential facts concerning the existence of Rose, $r$, outposts on Mars, myself, yourself etc. They also ground that $r$ is a dinosaur $r_{\varepsilon}$ is 66 million years earlier $\varepsilon_{\varepsilon}$ than my current temporal part etc.

\footnotetext{
9 A referee worried about the possibility of gunk. When faced with worries about fundamentality and gunk, the standard response is priority monism (Schaffer 2010b). More specifically, since time is tensed, we should endorse a version of Baron's 'priority presentism' (Baron 2015) whereby the entire present moment is fundamental, grounding all other facts (whether they're present facts or past/future facts). Were priority presentism true, we could allow for gunk by substituting all talk about fundamental facts about simples with talk about fundamental facts about the fusion of everything which presently exists. For instance, when we come to 'double bubble theory' (q.v.) we'd instead say that there are multiple fundamental facts about there being multiple presently existing universal wholes.

One last note: Priority presentism assumes there are instants. Given gunk exists, you might fear instants don't exist and instead that every interval has a sub-interval. But, given the dialectic, that's not an open option because tensed time requires some instant to be metaphysically privileged, thus 'temporal gunk' is ruled out; if there is gunk, it must be merely spatial.
} 
The second type of fundamental fact will be tensed and will change over time. They are 'concretizing facts', saying of the mereologically simple things that they are concrete. Those facts thereby ground the concreteness of all presently existing things (i.e. you, me, everyone we know, our temporal parts etc.) in addition to the mereological simples. We can then reduce presentness to concreteness i.e. to be present is for you to be concrete in virtue of these fundamental tensed facts.

Call this theory the single bubble theory of time because presently existing things form a concrete 'bubble' within the foam of merely abstract, non-present things. Being a moving spotlight theory cum presentist theory, it seems just as plausible as its tensed competitors (indeed Orilia (2016) already argues for a theory similar to that presented here). It seems obvious to me that those philosophers attracted to both permissiveness about ontology and presentism will find this the most natural ontology to endorse.

Single bubble theory has but one present. It is not hard to add in another. Consider the plurality of concretizing facts which the single bubble theorist says makes concrete those things which are present (i.e., right now at least, those things in 2020 AD). Call that plurality of facts ' $\mathrm{C}_{2020}$ '. Now imagine that there's a second collection of concretizing facts, in virtue of which Rose and $r$ (and all the things from 66 million BC) are concrete. Call that plurality of facts ' $\mathrm{C}_{66 \mathrm{~m}}$ '. There are correspondingly two collections of concreta: those inhabiting 2020 and those inhabiting 66 million BC. There are no multiple bubbles of concrete things and multiple present moments. Call that the double bubble theory of time.

\subsection{The First Problem for Multiple Nows}

With this system in place, consider temporal analogues of the problems from $\S 4.4$ This section explains how double bubble theory resolves them.

The temporal analogue of the first problem would be that, rather than there being two presents, there's only a single, larger, present. But consider $r$, the temporal part of Rose, and $n$, my current instantaneous temporal part. There is a relation between $r$ and $n$, namely that they're separated ${ }_{\varepsilon}$ by 66 million years. Were there to be two bubbles of presentness such that $r$ and $n$ were both present,

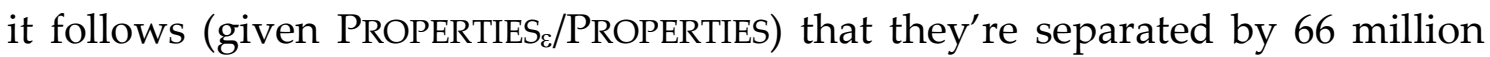
years. Similarly for the times they exist at, call them $t_{r}$ and $t_{n}$. Both $t_{r}$ and $t_{n}$ are separated by 66 million years s $_{\varepsilon}$, when they're both present, they're therefore separated by 66 million years. Since those times are temporally separated, they cannot be the same time! The first problem is solved.

Here's a possible complaint. I've stipulated of my system that two things are

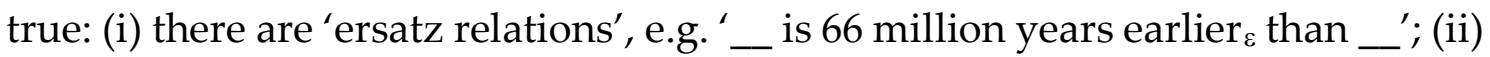
that PROPERTIES $\varepsilon$ /PROPERTIES is true and instantaneous temporal parts which are concrete are $\mathrm{F}$ if they are $\mathrm{F}_{\varepsilon}$. Maybe (ii) is false on the grounds that I can't simply 


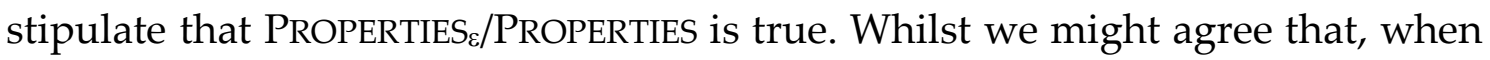
$t_{r}$ was present the first time, $t_{r}$ was 66 million years earlier than $t_{n}$, when I say it becomes present again the accusation would be that it's instead simultaneous with $t_{n}$ (even though it's still 66 million years earlier $\operatorname{than}_{\varepsilon} t_{n}$ i.e. even though it still stands in the relevant ersatz relation to me). That is, whilst I claim that

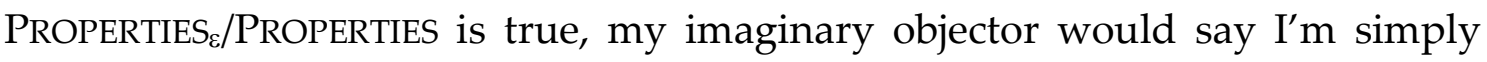
wrong-indeed, the possibility of multiple concretizing facts like $\mathrm{C}_{66 \mathrm{~m}}$ and $\mathrm{C}_{2020}$ would itself be taken to be a counterexample to the principle. But as far as I can see, the only reason to say this would be a dogged commitment to concreta having to be co-present with other concreta. And other tensed theorists already deny exactly that. For instance, moving spotlight theory says there are concrete things which aren't co-present, as does growing block theory. Double bubble theory would be in the same vein, sharing that feature. Thus, double bubble theory is at least as plausible as moving spotlight theory/growing block theorywhich is to say, very plausible indeed. ${ }^{10}$

\subsection{The Second Problem for Multiple Nows I}

The temporal analogue of the second problem from $\S 4.4$ is as follows. Let $Q$ be some proposition true in 2020 and false 66 million years ago. Where $N$ is the 'It is now the case...' operator, $N Q$ is true. Were I to time travel back to 66 million BC, making both times present, then $N Q \wedge N \neg Q$ would be true. Given either of the following principles, we get a contradiction:

\section{FACTIVITY OF PRESENTNESS: $N \varphi \supset \varphi$ \\ COMMUTATIVITY OF $\neg / N: N \neg \varphi \leftrightarrow \neg N \varphi$}

To solve this problem, double bubble theorists should co-opt some of the tenseless theorist's machinery. Tenseless theorists relativise the truth of tensed sentences to times. 'Rose the T-Rex currently weighs eight tonnes' isn't true simpliciter, rather it's true relative to some Cretaceous time. The double bubble theorist should follow suit ( $c f$ Dowe 2009, 663). Given there are multiple nows, it's only natural to relativise present truths to the 'now' to which they belong. $Q$ isn't simply true, it's true relative to some present moment.

The accusation will be one of heresy. Was not the whole point of tensed theory to avoid relativising truth to times like this ( $c f$ Dowe 2009, 663)? To defend against this charge, we should first clarify what is driving these worries about tenseless

\footnotetext{
${ }^{10}$ Of course, unlike moving spotlight theory, double bubble theory denies that all non-present things are concrete. But it should be of no surprise that the new tensed theory I'm developing disagrees with some claims of moving spotlight theory -it is, after all, a new theory.
} 
theory. Having done that, I can show that double bubble theory is nevertheless in-step with the motivations underlying tensed theory. ${ }^{11}$ Consider three possible drives for worrying about such relativisation.

First drive: We may worry that the tenseless theorist's relativisation of truth results in a theory which fails to allow reality to change. But double bubble theory is innocent of such heresy! Even were the truth of propositions relativised to the present moment, those truths nevertheless change in the fundamental way demanded by the tensed theorist. Right now, $\mathrm{C}_{2020}$ and $\mathrm{C}_{66 \mathrm{~m}}$ exist. But in a few moments time, these facts will change (and, say, $\mathrm{C}_{2020+\delta}$ and $\mathrm{C}_{66 \mathrm{~m}+\delta}$ will exist, where those facts respectively make concrete one time slightly later ${ }_{\varepsilon}$ in 66 million BC and another time slightly later $_{\varepsilon}$ in 2020 AD).

Second drive: We may worry that tenseless theory's relativisation of truth to a time leaves no room for people being in pain simpliciter (or being 6 ' tall simpliciter, or being a philosopher simpliciter etc.). Clearly the tenseless theorist can't allow this because, e.g., were I in pain simpliciter given tenseless theory, I would tenselessly be in pain (i.e. be in pain at every time), which is nonsense. But the double bubble theorist has none of these worries, even though they relativise truth to a time. The double bubble theorist admits that I can be in pain simpliciter. That fact holds jointly in virtue of (i) the tenseless fact that my instantaneous temporal part, $n$, is in $\operatorname{pain}_{\varepsilon}$ and (ii) the tensed fact that $n$ is concrete. In that it holds partially in virtue of a tensed fact, the fact that I am in pain simpliciter is

${ }^{11}$ Those puritanical about avoiding the machinery of the tenseless theorist could instead coopt fragmentalist thinking. Fine (2005) discusses alternatives to standard tensed theory. Let « $\varphi »$ be the name of 'the fact that $\varphi^{\prime}$. The standard realist about tense argues that the tensed facts which constitute reality change over time e.g. "Nikk Effingham is sitting» partially constitutes reality at the moment, but later «Nikk Effingham is standing» partially constitutes it. Fragmentalists (Hofweber and Lange 2017; Iaqunito 2019; Lipman 2015, 2016, 2018; Simon 2018; Torrengo and Iaqunito 2019) deny that facts change-«Nikk Effingham is sitting» and Nikk Effingham is standing» are both constituents of reality. Fragmentalists learn to live with this apparent incoherence by saying that different collections of facts form 'fragments' which make up reality. No fragment is more privileged than any other and, within each fragment, the facts 'co-obtain' and are mutually coherent.

We could install a fragmentalist-style solution, rather than a tenseless-style 'relativisation solution', into double bubble theory. The theory in the main text would have it that facts like " Nikk Effingham is sitting relative to present moment $t_{2020 »}$ and «Rose is eating relative to present moment $t_{66 \mathrm{~m}}$ ) constitute reality; those facts then change over time, just as in standard tense theory. The fragmentalist-style theory instead has it that reality is constituted by regular tensed facts (i.e. of the form "Nikk Effingham is standing» and «Rose is eating») which also change over time. And some of those tensed facts co-obtain, forming different fragments of reality. Unlike the normal fragmentalist theory, only some times - namely those which are present! - correspond to such fragments. (And just as fragmentalism has been extended to modality (Iaquinto Forthcoming), we could extend this fragmentalist riff on bubble theory to allow for multiple actualities.) 
likewise a tensed fact. So the double bubble theorist has room for my being in pain simpliciter without having to allow that I am in pain at every time. So if you are driven to deny the tenseless theorist's relativisation of truth to a time on these grounds, they are not a reason to disallow the double bubble theorist doing likewise.

Third drive: We may worry that the relativisation of truth fails to appropriately connect what's presently true to what's true simpliciter. Presentists, for instance, say that Nikk is in pain iff Nikk is in pain simpliciter. That's a bi-conditional which the tenseless theorist must deny. Indeed, FACTIVITY OF PRESENTNESS is just the left-to-right reading of that bi-conditional and this third drive presumably amount to a commitment to FACTIVITY OF PRESENTNESS.

The double bubble theorist cannot accept FACTIVITY OF PRESENTNESS. First, note that they can't accept it because they deny that there's an $N$ operator, having ditched it for a temporally-relativised operator, $N_{t}$. But they can't even accept an analogue of FACTIVITY OF PRESENTNESS which replaces the $N$ operator with the $N_{t}$ operator, i.e. they can't accept:

\section{RELATIVISED FACTIVITY: For any time $t, N_{t} \varphi \supset \varphi$.}

Double bubble theorists should say RELATIVISED FACTIVITY is false. Consider: There are no dinosaurs in 2020. ${ }^{12} 2020$ is present, thus presently (relative to 2020 $\mathrm{AD})$ there are no dinosaurs. Given RELATIVISED FACTIVITY there are no dinosaurs. However, there are dinosaurs in 66 million BC. 66 million BC is also present, thus presently (relative to 66 million BC) there are dinosaurs. Given RELATIVISED FACTIVITY there are dinosaurs. Hence there both are and are not dinosaurs - a contradiction! So the double bubble theorist cannot even accept an $\boldsymbol{N}_{t}$ - analogue of FACTIVITY OF PRESENTNESS.

But this doesn't mean that the double bubble theorist cannot accept a relationship between truth-at-a-time and truth simpliciter which is suitably similar to that which the presentist accepts. Start by considering what the double bubble theorist can accept. Demarcate propositions into two categories: positive propositions saying what is the case and negative propositions saying what is not the case. For instance, 〈Nikk Effingham is in pain〉 and 〈Dinosaurs exist〉 are positive propositions whilst $\langle\neg$ Rose is in pain $\rangle$ and $\langle\neg$ Unicorns exist $\rangle$ are negative propositions. ${ }^{13}$ Unlike the tenseless theorist, and like the presentist, the double bubble theorist can accept that a positive proposition is presently true iff it's true simpliciter. Take a God's eye view of reality looking at both bubbles which

\footnotetext{
${ }^{12}$ Rose still exists in 2020. But she's no dinosaur, at best presently being a mere dinosaur $\varepsilon_{\varepsilon}$.

${ }^{13}$ The division between negative and positive propositions is notoriously fraught. For reasons of space I will have to ignore those worries in this paper.
} 
presently exist. God sees, in one bubble, that I am presently in pain. Similarly, God sees that I am in pain simpliciter. Restricted just to positive propositions, God sees that there's a connection between truth-at-a-time and truth simpliciter similar to the connection the presentist thinks there is (and which the tenseless theorist does not). What the double bubble theorist denies is that the same can be said of negative propositions. Return to the God's eye view. God sees two bubbles, in one of which dinosaurs don't presently exist i.e. $\left\langle\boldsymbol{N}_{2020}\right\urcorner$ Dinosaurs exist $\rangle$ is true. But God can see that dinosaurs do exist simpliciter since Rose exists simpliciter in the other bubble, roaming around the other concrete 'now'. So the connection clearly fails for negative propositions. In short, double bubble theorists should only accept:

POSITIVE FACTIVITY: For any time $t$, and any positive proposition $\psi, N_{t} \psi \supset$ $\psi$.

POSITIVE FACTIVITY doesn't cause the double bubble theorist problems in the way that RELATIVISED FACTIVITY and FACTIVITY OF PRESENTNESS do. And POSITIVE FACTIVITY does capture an intimate connection between what's true at a time and what's true simpliciter - certainly it captures a relationship in a way the presentist alleges the tenseless theorist is unable to do so. So whilst the double bubble theory relativises truth to a time, they can nevertheless accept-with the presentist - that there is an intimate connection between truth at a time and truth simpliciter. ${ }^{14}$

\subsection{The Second Problem for Multiple Nows II}

$\$ 6.3$ explained why FACTIVITY OF PRESENTNESS is false. That just leaves COMMUTATIVITY OF $\neg / N$. The double bubble theorist denies that principle, since there's no $N$ operator. The double bubble analogue of COMMUTATIVITY OF $\neg / N$ is:

\section{COMMUTATIVITY OF $\left.\neg / N_{t}: N_{t}\right\urcorner \varphi \leftrightarrow \neg N_{t} \varphi$}

And that principle is unproblematic. Assume $Q$ was true in 2020 and false in 66 million BC. Only $N_{2020} Q \wedge N_{66 m} \neg Q$ follows from this and COMMUTATIVITY OF $\neg / N_{t}$ will then entail no contradiction.

\footnotetext{
${ }^{14}$ One might think contradictions still lurk in the wings. Imagine I am $6^{\prime}$ tall and time travel from 2020 to 1985 . In 1985 , my younger self was $4^{\prime}$ tall. $\left\langle N_{2020:}\right.$ Nikk is $6^{\prime}$ tall $\rangle$ and $\left\langle N_{1985:}\right.$ Nikk is $4^{\prime}$ tall $\rangle$ are both true; both are positive propositions, thus (given RESTRICTED FACTIVITY) 〈Nikk is 6' tall $\wedge$ Nikk is $4^{\prime}$ tall $\rangle$ is true. That looks contradictory. However, I don't think this is a problem. I give a fuller discussion elsewhere (Effingham 2020, 29; 34-5).
} 
This finishes my exposition of a metaphysical system allowing for there to be multiple nows.

\section{The Metaphysics of Multiple Actualities}

\subsection{Modal Bubble Theory}

Having developed a metaphysical system underpinning there being multiple nows, we can now port that over and develop a metaphysical system underpinning there being multiple actual worlds. Call it modal bubble theory. $\S 4.2$ introduced three parts of this theory already: (i) everything is composed of modal parts (with ersatz properties $\xi$ ); (ii) all possible things necessarily exist (and if they're not actualised, they're abstract); (iii) some fusions of modal parts are possible worlds.

To this picture we now add in grounding relations. Mirroring double bubble theory's focus on fundamental facts being about mereological simples, modal bubble theory can follow suit, saying that the fundamental facts are all about the existence and nature of modal parts of instantaneous temporal parts of spatial simples. These fundamental facts ground all facts about what exists, the properties $\xi$ of those things, and the relations $\xi$ between those things. (We should also add that there'll be fundamental facts saying which fusions of those things count as being possible worlds; recall, I'm making no effort to analyse away modality.)

Not only are there necessary fundamental facts, there are contingent fundamental facts (so the theory is 'actualist'). Those contingent facts are concretizing facts saying which mereologically simple things are concrete. It is in virtue of these contingent facts that everything which is actual is concrete (or, if you further endorse temporal bubble theory: everything which is both actual and present is concrete). For instance, where $w_{\alpha}$ is the world we generally regard as the actual world, there's a collection of fundamental concretizing facts, $\mathrm{C}_{\alpha}$, in virtue of which our world is concrete i.e. in virtue of which the mereological simples composing $w_{\alpha}$ are concrete. God can actualise multiple worlds by making extra contingent concretizing facts. For instance, further to $\mathrm{C}_{\alpha}$ (in virtue of which $w_{\alpha}$ is concrete) God can make $w_{\beta}$ and $w_{\chi}$ actual by making two more collections of concretizing facts, $\mathrm{C}_{\beta}$ and $\mathrm{C}_{\chi} \cdot{ }^{15}$

\footnotetext{
15 There's another theory, patchwork theory, which is footnote worthy. Patchwork theory has it that God actualises only parts of worlds, without making concrete the entire world. In that case, many more things can be made concrete than otherwise. For instance, if there's a world where I live a perfect life but some agents live lives not worth living, then the appropriate axiological principle (\$2) prevents God making that world. But given patchwork theory, God concretises my
} 


\subsection{Solving Problems}

This in place, we can now solve the problems, mooted in $\$ 4.4$, facing multiple actualities. The solutions all mirror those from $\S 6.3-6.5$.

The first worry is that God, in making $C_{\alpha}, C_{\beta}$ and $C_{\chi}$, is just making one really big actual world consisting of island universes. But modal bubble theory is an extension of the theory sketched in $\S 4$.2. That original sketch says that worlds are fusions of modal parts - exactly which fusions being a matter of brute fact. Modal bubble theory agrees with this and will likewise agree over which fusions of modal parts qualify as worlds. So both theories agree that there are some modal parts which compose $w_{\alpha}$, some which compose $w_{\beta}$, some which compose $w_{\chi}$, and that it's a brute fact that these fusions are worlds. Thus if $C_{\alpha}, C_{\beta}$ and $C_{\chi}$ are all concretezing facts then there must be three different worlds. It's just built into the theory!

One might come down hard against this and say that if things are concrete then they must be co-actual. But there's already a theory out there which denies just this, namely Lewis's genuine modal realism (1986). In the same way that double bubble theory allied itself to moving spotlight theory's commitment to the possibility of concreta being non-simulataneous, modal bubble theory allies itself to genuine modal realism's commitment to the possibility of concreta failing to be co-actual. ${ }^{16}$

The next problem was that a contradiction followed given:

FACTIVITY OF ACTUALITY: A $\varphi \supset \varphi$

Modal bubble theory has no actuality operator, $A$. Instead, there's an actuality operator which relativises truth to a metaphysically privileged/concrete world. Represent that operator using ' $\boldsymbol{A}_{\partial}$ '. Rather than FACTIVITY OF ACTUALITY we should endorse the unproblematic:

POSITIVE FACTIVITY OF ACTUALITY: For any metaphysically privileged world, $\partial$, and any positive proposition $\psi, A_{\partial} \psi \supset \psi$.

modal parts at that world even though agents who suffer $\xi$ intolerable evils are left being merely non-concrete (and thus suffering no evils at all). This has the weird upshot that I might be having a conversation with someone who isn't a concrete existent. That's very weird-perhaps so weird that the theory is unbelieable. It's nevertheless worth noting.

${ }^{16}$ And, in the same way that double bubble theory denied the moving spotlight theory's commitment to all non-present things being concrete (see $f n$ 9), the modal bubble theorist will deny the genuine modal realist's commitment to all possibilia being concrete. Only some possibilia are concrete, according to the modal bubble theorist. 
Similarly, there's a problem given:

$$
\text { COMMUTATIVITY OF } \neg / A: A \neg \varphi \leftrightarrow \neg A \varphi
$$

But the modal bubble theorist should instead endorse the unproblematic:

$$
\text { COMmutativity Of } \left.\neg / A_{\partial \partial} A_{\partial}\right\urcorner \leftrightarrow \leftrightarrow \neg A_{\partial \varphi}
$$

Thus both problems are dissolved if we relativise actuality in this manner. And just as I see no problem with the tensed theorist relativising actuality to present moments, I see no problem with modal bubble theorists relativising actuality to concretized worlds.

\subsection{Back to the Duplication Objection}

All of this was in aide of developing a theory similar to the Multiverse Response which avoids the Duplication Objection. At the end of $\$ 4.1$ I explained why multiple actual worlds avoid an analogue of the Duplication Objection: God can make duplicate universes but (given WORLD INDIVIDUATION) it makes no sense to allow for duplicate worlds. So if God wants more worlds than the perfect oneand He should if He can actualise them! - then He has to actualise imperfect worlds.

Further to that argument, having laid out the modal metaphysical system as I have, there are two other ways to make a similar point. This section lays them out. They complement, and do not replace, the thinking from $\S 4.1$.

Given the modal metaphysical system, all parties - regardless of whether they believe God actualises one world or many - should agree that exactly the same worlds (and modal parts) exist. All parties to the debate should also agree which worlds are perfect. Given the Multiactualities Response, God actualises those perfect worlds (which, given modal bubble theory, amounts to making them concrete). God then sees that there are yet more worlds He could make concrete which (given §4.3) would make reality as a whole a better place. Thus God makes them concrete/actualises them as well. That means, assuming our world meets that axiological standard, God makes concrete our world.

A complaint analogous to the Duplication Objection would be that when God actualises the world I live in, God should also have made my life better at this world. But the machinery of possible worlds and modal parts will help make clear why this problem goes away. To wonder why God didn't make my life better is to wonder about a modal claim - it is to wonder about why God didn't actualise a world at which my life is better. But God did actualise that world! He just also went on to actualise the world where my life's not as good. (Note the 
difference to the Multiverse Response. Given the Multiverse Response, God merely concretizes a universe where someone like me has a better life. In this case, God concretizes me having that better life.)

Here's another way to put a similar idea. In $\S 4.3$ I argued that God should want to make actual as many modal parts of me as possible, just as long as they meet the relevant axiological standard. So God starts by actualising a world at which Nikk lives a perfect life. Having actualised that world, God then decides to also actualise the world we see around us. The reason God does this is not to bring Nikk into concrete existence since I am already a concrete existent at some other world where I live a perfect life. As $\$ 4.3$ argued, the motivation for God to actualise this world is to actualise the 'this-worldly modal part' of Nikk. And, unlike me, my modal parts are worldbound entities which exist (by necessity!) at only one world. Thus my 'this-worldly modal part' is (by necessity!) such that it suffers evils. Hence, if God wants to actualise that modal part (which, as $\S 4.3$ defended, He does) then He has to actualise an imperfect world along with it. Again, we can't say similar things in the case of the Multiverse Response. Given the Multiverse Response, God makes more universes in order to create extra people rather than extra modal parts. And when God creates an extra person, it's true of that person that their life could have been better, at which stage God is faced by the awkward question of why He didn't make that person's life better. Since, by necessity, God could not have made my 'this-worldly modal part' better off than it is, the same simply cannot be said of modal parts.

The arguments in this section may appear to make the ontology of modal parts central. This is merely an appearance. Consider cases where philosophers talk about temporal parts when it's easy and perspicuous to do so, without necessarily committing to perdurantism. It's legitimate to do this because they can talk about temporal parts full in the knowledge that a workable endurantist theory should be able to translate any helpful temporal parts talk back into endurantist terms. For instance, an endurantist who doesn't believe in temporal parts should nevertheless be able to accept the thrust of $\S 4.3$ 's argument that it's good for me to live a longer life even if my life is less perfect than it once was. Such endurantists would just cash the argument out in endurantist-friendly terms, rather than using temporal parts talk. Similarly, I'm using modal part talk as an expository device. Were you to endorse a rival theory to modal parts (e.g. counterpart theoretic accounts (Lewis 1968), anti-realist competitors (Rosen 1990), etc.) then, assuming that the rival theory is worth its salt, you should be able to parse what I've said into your own terms without affecting the thrust of the arguments presented here. 


\section{Conclusion}

The Multiverse Response's big problem is the Duplication Objection. We can overcome that Objection by recasting the Multiverse Response as a case of God actualising multiple possible worlds, rather than universes. The big problem for this new theory is that prima facie it makes no sense to talk of multiple actual worlds. But considerations in the philosophy of time travel lead us to believe there can be multiple nows; by analogy, there can be multiple actual worlds. Thus we have a new, workable and interesting, response to the problem of evil.

\section{Bibliography}

Almeida, M. 2008. The Metaphysics of Perfect Beings, London: Routledge.

Almeida, M. 2017. "Theistic Modal Realism II: Theoretical Benefits." Philosophy Compass 12/7. https://doi.org/10.1111/phc3.12418.

Baron, S. 2015. "The Priority of the Now." Pacific Philosophical Quarterly 96, 32548. https://doi.org/10.1111/papq.12030.

Black, M. 1952. "The Identity of Indiscernibles." Mind 61, 153-64. https://doi.org/10.1093/mind/LXI.242.153.

Bliss, R. and Trogdon, K. 2014. "Metaphysical Grounding." Stanford Encyclopedia of Philosophy (Winter 2016 Edition), edited by Edward N. Zalta, URL = https://plato.stanford.edu/archives/win2016/entries/grounding/.

Climenhaga, N. 2018. "Infinite Value and the Best of All Possible Worlds." Philosophy and Phenomenological Research 67, 367-92. https://doi.org/10.1111/phpr.12383.

Dowe, P. 2009. "Every Now and Then: A-Theory and Loops in Time." The Journal of Philosophy 106, 641-65. https://doi.org/10.5840/jphil20091061223.

Draper, P. 2004. "Cosmic Fine-Tuning and Terrestrial Suffering: Parallel Problems for Naturalism and Theism." American Philosophical Quarterly 41, 311-21.

Effingham, N. 2016. "Review of Almeida's “The Metaphysics of Perfect Beings"." European Journal for Philosophy of Religion 8, 243-7. https://doi.org/10.24204/ejpr.v8i4.1782.

Effingham, N. 2020. Time Travel: Probability and Impossibility. Oxford: Oxford University Press. https://doi.org/10.1093/oso/9780198842507.001.0001.

Fine, K. 2005. Modality and Tense: Philosophical Papers, Oxford: Oxford University Press. https://doi.org/10.1093/0199278709.001.0001.

Forrest, P. 1981. "The Problem of Evil: Two neglected defences." Sophia 20, 49-54. https://doi.org/10.1007/BF02782747.

Goff, P. 2010. "Could the Daleks have stopped the pyramids being built?" In Doctor Who and Philosophy, edited by Lewis and Smithka, Open Court: Chicago. 
Graham, A. 2015. "From Four- to Five-Dimensionalism." Ratio 28, 14-28. https://doi.org/10.1111/rati.12049.

Hofweber, T. and Lange, M. 2017. “Fine's Fragmentalist Interpretation of Special Relativity." Noûs 51, 871-83. https://doi.org/10.1111/nous.12150.

Hudson, H. 2008. The Metaphysics of Hyperspace, Oxford: Oxford University Press. https://doi.org/10.1111/j.1933-1592.2007.00142.x.

Iaqunito, S. 2019. "Fragmentalist Presentist Perdurantism." Philosophia 47, 693703. https://doi.org/10.1007/s11406-018-0016-4.

Iaqunito, S. Forthcoming. "Modal Fragmentalism." The Philosophical Quarterly.

Johnson, D. 2014. "The Failure of the Multiverse Hypothesis as a Solution to the Problem of No Best World." Sophia 53, 447-65. https://doi.org/10.1007/s11841013-0397-6.

Kraay, K. 2010a. "Theism, possible worlds, and the multiverse." Philosophical Studies 147, 355-68. https://doi.org/10.1007/s11098-008-9289-y.

Kraay, K. 2010b. "The problem of no best world." In A Companion to Philosophy of Religion $2^{\text {nd }}$ Edition, edited by Taliaferro, Draper, and Quinn. Oxford: WileyBlackwell.

Kraay, K. 2013. “Megill's multiverse meta-argument." International Journal for Philosophy of Religion 73, 235-241. https://doi.org/10.1007/s11153-011-9324-3.

Lewis, D. 1983. "Counterpart Theory and Quantified Modal Logic." The Journal of Philosophy 65, 113-26. https://doi.org/10.2307/2024555.

Lewis, D. 1986. On the Plurality of Worlds, Oxford: Blackwell.

Lipman, M. 2015. “On Fine's Fragmentalism.” Philosophical Studies 172, 3119-33. https://doi.org/10.1007/s11098-015-0460-y.

Lipman, M. 2016. "Perspectival Variance and Worldly Fragmentation." Australasian Journal of Philosophy 94, 42-57. https://doi.org/10.1080/00048402.2015.1020503.

Lipman, M. 2018. "A Passage Theory of Time." Oxford Studies in Metaphysics 11, 95-122. https://doi.org/10.1093/oso/9780198828198.003.0003.

McHarry, J. 1978. "A Theodicy." Analysis 38, 132-34. https://doi.org/10.1093/analys/38.3.132.

Megill, J. 2011. "Evil and the many universes response." International Journal for Philosophy of Religion 70, 127-138. https://doi.org/10.1007/s11153-010-9280-3.

Monton, B. 2010. "Against multiverse theodicies." Philo 13, 1-23. https://doi.org/10.5840/philo20101321.

Orilia, F. 2016. "Moderate Presentism." Philosophical Studies 173, 589-607. https://doi.org/10.1007/s11098-015-0508-z.

Parfit, D. 1992. “The Puzzle of Reality: Why does the universe exist?" Times Literary Supplement 3 July 1992.

Rosen, G. 1990. "Modal Fictionalism." Mind 99, 327-54. https://doi.org/10.1093/mind/XCIX.395.327. 
Rubio, D. Forthcoming. "In Defence of No Best World." Australasian Journal of Philosophy.

Ruhmkorff, S. 2019. “The Copernican Principle, intelligent extraterrestrials, and arguments from evil." Religious Studies 55, 297-317. https://doi.org/10.1017/S0034412518000045.

Saunders, S. and Wallace, D. 2008. "Branching and Uncertainty." British Journal for the Philosophy of Science 59, 293-305. https://doi.org/10.1093/bjps/axn029.

Schaffer, J. 2010a. "In What Grounds What." In Metametaphysics: New Essays on the Foundations of Ontology, edited by Chalmers, Manley, and Wasserman. Oxford: Oxford University Press.

Schaffer, J. 2010b. "Monism: The Priority of the Whole." Philosophical Review 2010, 31-76. https://doi.org/10.1215/00318108-2009-025.

Simon, J. 2018. "Fragmenting the Wave Function." Oxford Studies in Metaphysics 11, 123-47. https://doi.org/10.1093/oso/9780198828198.003.0004.

Skow, B. 2015. Objective Becoming, Oxford: Oxford University Press. https://doi.org/10.1093/acprof:oso/9780198713272.001.0001.

Spolaore, G. and Torrengo G. Forthcoming. "The moving spotlight(s)." Inquiry.

Steinhardt, P. and Turok, N. 2002. "A Cyclic Model of the Universe." Science 296, 1436-39. https://doi.org/10.1126/science.1070462.

Tegmark, M. 2003. "Parallel Universes." In Science and Ultimate Reality: From Quantum to Cosmos, edited by John D. Barrow, Paul C. W. Davies, and Charles L. Harper Jr. Cambridge: Cambridge University Press. https://doi.org/10.1017/CBO9780511814990.024.

Torrengo, G. and Iaquinto, S. 2019. "Flow Fragmentalism." Theoria 85, 185-201. https://doi.org/10.1111/theo.12182.

Turner, D. 2003. "The Many-Universes Solution to the Problem of Evil." In The Existence of God, edited by Gale and Pruss, A. Aldershot: Ashgate.

Pruss, A. 2015. "Revisiting the Many-Universes Solution to the Problem of Evil." In God and the Multiverse: Scientific, Philosophical, and Theological Perspectives, edited by in Kraay. London: Routledge.

Wallace, M. 2014. “The Argument from Vagueness for Modal Parts." Dialectica 68, 355-73. https://doi.org/10.1111/1746-8361.12073. 